Conclusion Aclidinium $200 \mu \mathrm{g}$ and $400 \mu \mathrm{g}$ twice daily provided clinically meaningful improvements in bronchodilation, health status, symptoms, breathlessness and exacerbation rate. Aclidinium was well tolerated with a similar safety profile for both doses; the incidence of AEs was similar to placebo.

Funding This study was supported by Almirall S.A., Barcelona, Spain, and Forest Laboratories, Inc., New York, USA.

\section{P256 ACLIDINIUM BROMIDE: A PHASE IIB, DOSE-FINDING STUDY}

doi:10.1136/thoraxjnl-2011-201054c.256

${ }^{1} \mathrm{D}$ Singh, ${ }^{2} \mathrm{H}$ Magnussen, ${ }^{2} \mathrm{~A}$ Kirsten, ${ }^{3} \mathrm{~S}$ Mindt-Pruefert, ${ }^{4} \mathrm{C}$ Caracta, ${ }^{5} \mathrm{D}$ Jarreta, ${ }^{5} \mathrm{E}$ Garcia Gil. 'Medicines Evaluation Unit, University of Manchester, Manchester, UK; 2Pulmonary Research Institute, Hospital Grosshansdorf, Grosshansdorf, Germany; ${ }^{3}$ Klinische Forschung Hamburg GmbH, Hamburg, Germany; ${ }^{4}$ Forest Research Institute, New Jersey, USA; ${ }^{5}$ Almirall S.A., Barcelona, Spain

Introduction and Objectives Aclidinium bromide, a second-generation, long-acting muscarinic antagonist with low systemic activity, is in clinical development for the twice daily maintenance treatment of chronic obstructive pulmonary disease (COPD). This Phase IIb study investigated the dose-response bronchodilation of aclidinium twice daily vs placebo and an active control (formoterol $12 \mu \mathrm{g}$ twice daily) in patients with moderate to severe COPD.

Methods In this double-blind, double-dummy, cross-over study, 79 patients received 7-day treatments of aclidinium $100 \mu \mathrm{g}, 200 \mu \mathrm{g}$ and $400 \mu \mathrm{g}$, formoterol $12 \mu \mathrm{g}$ and placebo twice daily over five treatment periods separated by a 7-day washout. The primary endpoint was change from baseline in normalised forced expiratory volume in 1 second $\left(\mathrm{FEV}_{1}\right)$ area under the curve (AUC) $)_{0-12}$ at Day 7. Other efficacy assessments included change from baseline at Day 7 in normalised $\mathrm{FEV}_{1} \mathrm{AUC}_{0-24}$ and morning pre-dose (trough) and peak $\mathrm{FEV}_{1}$. Adverse events (AEs) were reported throughout the study.

Results Aclidinium provided dose-dependent bronchodilation compared with placebo as assessed by change from baseline in normalised $\mathrm{FEV}_{1} \mathrm{AUC}_{0-12}$ and $\mathrm{FEV}_{1} \mathrm{AUC}_{0-24}$ at Day 7 (Abstract P256 table 1). The bronchodilation provided by aclidinium $400 \mu \mathrm{g}$ during the first $12 \mathrm{~h}$ was comparable to the active control, formoterol $12 \mu \mathrm{g}$. Aclidinium improved morning pre-dose trough $\mathrm{FEV}_{1}$ and peak $\mathrm{FEV}_{1}$ after 7 days compared with placebo; the $400 \mu \mathrm{g}$ dose was most comparable to formoterol $12 \mu \mathrm{g}$. Aclidinium was well tolerated; the safety profile of all doses was comparable to that of placebo.

Abstract P256 Table 1 Adjusted mean (SE) change from baseline (L) on Day 7

\begin{tabular}{llllll}
\hline & $\begin{array}{l}\text { Aclidinium } \\
\mathbf{1 0 0} \boldsymbol{\mu g}\end{array}$ & $\begin{array}{l}\text { Aclidinium } \\
\mathbf{2 0 0} \boldsymbol{\mu g}\end{array}$ & $\begin{array}{l}\text { Aclidinium } \\
\mathbf{4 0 0} \boldsymbol{\mu g}\end{array}$ & $\begin{array}{l}\text { Formoterol } \\
\mathbf{1 2} \boldsymbol{\mu g}\end{array}$ & Placebo \\
\hline Normalised & $0.128^{*}$ & $0.151^{*}$ & $0.183^{*}$ & $0.185^{*}$ & -0.026 \\
$\mathrm{FEV}_{1} \mathrm{AUC}_{0-12 \mathrm{~h}}$ & $(0.022)$ & $(0.022)$ & $(0.022)$ & $(0.022)$ & $(0.022)$ \\
Normalised & $0.089^{*}$ & $0.100^{*}$ & $0.133^{*}$ & $0.163^{*}$ & -0.062 \\
$\mathrm{FEV}_{1} \mathrm{AUC}_{0-24 \mathrm{~h}}$ & $(0.021)$ & $(0.021)$ & $(0.021)$ & $(0.020)$ & $(0.021)$ \\
Morning & $0.081^{*}$ & $0.089^{*}$ & $0.130^{*}$ & $0.123^{*}$ & -0.025 \\
pre-dose FEV & $(0.023)$ & $(0.023)$ & $(0.023)$ & $(0.023)$ & $(0.023)$ \\
Morning & $0.287^{*}$ & $0.299^{*}$ & $0.340^{*}$ & $0.344^{*}$ & 0.098 \\
peak FEV & $(0.023)$ & $(0.023)$ & $(0.023)$ & $(0.023)$ & $(0.023)$ \\
\hline
\end{tabular}

${ }^{*} \mathrm{p}<0.0001$ vs placebo.

Conclusion A dose-dependent bronchodilation was observed with aclidinium twice daily. The bronchodilation provided by the highest dose of aclidinium $(400 \mu \mathrm{g})$ twice daily was comparable to formoterol $12 \mu \mathrm{g}$ twice daily. The safety profile of aclidinium was similar to placebo, with no dose-dependent AEs observed.

Funding This study was supported by Almirall S.A., Barcelona, Spain, and Forest Laboratories, Inc., New York, USA.

\section{P257 EFFECTS OF EXTRA-FINE INHALED AND ORAL CORTICOSTEROIDS ON ALVEOLAR NITRIC OXIDE IN COPD}

doi:10.1136/thoraxjnl-2011-201054c.257

P M Short, P A Williamson, B J Lipworth. Asthma and Allergy Research Group, Ninewells Hospital and Medical School, University of Dundee, Dundee, UK

Introduction and Objectives Alveolar nitric oxide or $\left(\mathrm{CA}_{\mathrm{NO}}\right)$, has been used as a surrogate marker of distal airway inflammation, which isimportant in COPD. Coarse particle inhaled corticosteroids (ICS) have been shown not to suppress $\mathrm{CA}_{\mathrm{NO}}$. We evaluated whether extra-fine particlesize inhaled corticosteroids (HFA-BDP) or systemic oral corticosteroids could suppress $\mathrm{CA}_{\mathrm{NO}}$ in COPD.

Methods COPD patients with a smoking pack history $>15$ years, $\mathrm{FEV}_{1} / \mathrm{FVC}$ ratio $<0.7, \mathrm{FEV}_{1}<80 \%$ predicted with small airways inflammation characterised by CANO $>2$ ppb underwent a doubleblind randomised controlled crossover trial with an open label systemic steroid comparator. Following a $2 \mathrm{wk}$ steroid washout period, patients were randomised to 3 weeks, 100 mcg HFA-BDP twice daily and then 3 weeks 400 mcg HFA-BDP twice daily or matched placebos with subsequent crossover. All patients then received 1 week openlabel, $25 \mathrm{mg} /$ day prednisolone. Spirometry, bodyplethysmography, impulse oscillometry, plasma cortisol and exhaled nitric oxide were recorded. $\mathrm{CA}_{\mathrm{NO}}$ was corrected for axial diffusion.

Results 16 patients completed per protocol. Compared to respective placebo there were no significant differences seen with either dose of HFA-BDP. Oral prednisolone caused a significant reduction in $\mathrm{FE}_{\mathrm{NO}}$ and J'aw ${ }_{N O}$ but not $\mathrm{CA}_{\mathrm{NO}}$. Plasma cortisol was significantly suppressed by oral prednisolone compared to all other treatments. There was no suppression seen with HFA-BDP at either dose verses placebo.

Conclusions While $\mathrm{CA}_{\mathrm{NO}}$ remains a biomarker of interest in COPD, it is not suppressed by systemic or extra-fine particle ICS. Hence $\mathrm{CA}_{\mathrm{NO}}$ is unlikely to be a useful marker for monitoring response of small airway disease to therapies in COPD.

\section{P258 ROLE OF 7-DAY AND 14-DAY COURSES OF ORAL PREDNISOLONE TREATMENT IN ACUTE EXACERBATION OF COPD}

doi:10.1136/thoraxjnl-2011-201054c.258

S M Abdullah Al Mamun, S Rahman. Sher E Bangla Medical college, Barisal, Bangladesh

Purpose The purpose of this study was to compare the efficacy of 7 day and 14-day courses of oral prednisolone treatment in patients with acute exacerbation of COPD with $\mathrm{FEV}_{1}<50 \%$ predicted.

Methods It was a prospective randomised, single blind study in a tertiary care centre, the study patients were included and randomised into two groups: 7-day group received oral prednisolone $30 \mathrm{mg} /$ day for 7 days, and 14-day group was administered the same dosage of oral prednisolone for 14 days. There was no significant difference between the groups for age, smoking pack years, symptoms of COPD in years, no. of previous exacerbations, blood eosinophilia, baseline $\mathrm{FEV}_{1}$, and FVC levels. One patient from 7-day group developed pneumothorax and one from 14-day group died of acute Myocardial Infarction.

Results Both groups showed significant improvements of $\mathrm{FEV}_{1}$ and FVC on D-1, D-3, D-5, D-7, D-10 and Day-14 from the baseline (7day group, $\mathrm{p}=0.0001,0.0001,0.008,0.009,0.008,0.011$ and 14 -day group, $p=0.000,0.000,0.000,0.000,0.000,0.000)$ and the improvement of FVC is also significant in both the groups, but there was no significant difference of improvement between the two groups on day-7 and day-14 ( $p=0.100,0.079)$. There was also significant improvement of symptom score from baseline on day-7 and day-14, but no significant difference of improvement between two groups. 
Conclusion In acute exacerbation of COPD there is no difference between 7-day and 14-day courses of treatment with oral prednisolone. The peak of $\mathrm{FEV}_{1}$ and FVC in 7-day group on day-10 where corticosteroid was already stopped on day-7, (peak in 14-day group was on day-7) might be due to some other factor/factors responsible which would be cleared by further study.

Clinical implications There was no difference between 7-day and 14day courses of prednisolone treatment, so, 7-day might be the shortest effective course of steroid treatment in acute exacerbation of COPD to avoid the burden of cost and side effects.

\section{P259 EFFECTS OF METFORMIN ON CLINICAL OUTCOME IN PATIENTS HOSPITALISED FOR COPD EXACERBATIONS: A RETROSPECTIVE COHORT STUDY}

doi:10.1136/thoraxjnl-2011-201054c.259

A W Hitchings, L Hayes, G Picton, L Turner, R Cull, S Aslam, J R H Archer, S A Srivastava, E H Baker. St George's, University of London, London, UK

Background Approximately 10\% of patients with chronic obstructive pulmonary disease (COPD) have co-existing diabetes mellitus, conferring an adverse prognosis. Metformin is a valuable first-line treatment for diabetes. However, its rare association with lactic acidosis limits its use among patients at risk of hypoxia. This may deter some practitioners from prescribing it to patients with significant co-existing COPD. It is unknown whether the benefits of metformin outweigh its risks in this context. We therefore sought to determine the effects of metformin on survival and length of stay in a high-risk cohort of diabetic patients hospitalised for COPD exacerbations.

Methods The medical records of diabetic patients hospitalised for COPD were reviewed retrospectively. Length of hospital stay and all-cause mortality were compared according to the presence or absence of metformin therapy.

Results 130 patients were included, of whom 51 (39\%) were prescribed metformin. Patients on metformin had a shorter hospital stay (median 7 vs 9 days respectively; $\mathrm{p}=0.004$ ). Survival at 90 days was significantly better in the metformin group than in the nonmetformin group (94\% vs $78 \%$ respectively; $\mathrm{p}=0.015$; Abstract $\mathrm{P} 259$ figure 1 inset). This persisted over the longer term, with overall median $(95 \% \mathrm{CI})$ survival of 5.2 years (4.3 to 6.1$)$ in the metformin group and 2.2 years (1.0 to 3.3 ) in the non-metformin group (HR

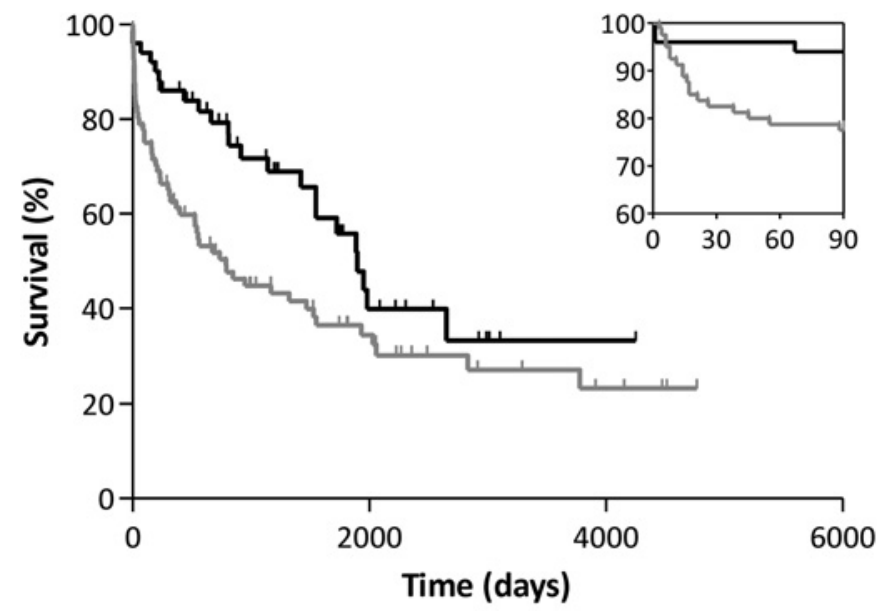

- Metformingroup - Non-metformin group

Abstract P259 Figure 1 Kaplan-Meier curves for all-cause mortality, divided according to metformin use ( $p=0.024$, log-rank test). Inset: survival curves at 90 days ( $p=0.015$, log-rank test).
0.57; 95\% CI 0.35 to 0.94; Abstract P259 figure 1). This difference remained significant in a multivariate model, adjusting for potential confounding effects of age, weight, acute illness severity (APACHEII score) and comorbidity burden. Among patients prescribed metformin, vs those not, the median (IOR) plasma lactate concentration was $1.45 \mathrm{mmol} / \mathrm{l}(1.10-2.05)$ vs $1.10 \mathrm{mmol} / \mathrm{l}(0.80-1.50)$, respectively $(\mathrm{p}=0.012)$.

Conclusion Diabetic patients hospitalised for COPD exacerbations who were prescribed metformin were discharged earlier and survived longer than those not prescribed metformin. Lactate concentration was higher among patients on metformin, although the difference was small. Our results suggest that the drug's benefits may outweigh its rare association with lactic acidosis. Whether this reflects beneficial effects on diabetes- or COPD-related endpoints; other associated conditions; or the effect of unmeasured confounders, is unknown. We are now investigating this within the context of a randomised controlled trial (ISRCTN66148745).

\section{P260 ORAL NUTRITIONAL SUPPLEMENTS IN CHRONIC OBSTRUCTIVE PULMONARY DISEASE (COPD): A SYSTEMATIC REVIEW AND META-ANALYSIS}

doi:10.1136/thoraxjnl-2011-201054c.260

P F Collins, R J Stratton, M Elia. Institute of Human Nutrition, School of Medicine, University of Southampton, Southampton, England

Oral nutritional supplements (ONS) are often used to treat malnutrition in COPD, but the latest Cochrane review in COPD concluded that nutrition support, mainly involving ONS, did not improve anthropometry and other functional outcomes. ${ }^{1}$ The latest NICE guidelines for the management of COPD recommend the use of ONS but state it is based on grade $\mathrm{D}$ evidence ${ }^{2}$ despite previous reviews suggesting otherwise. ${ }^{3}$ This review aimed to clarify the evidence base for ONS use in COPD. A systematic review identified 11 randomised controlled trials using ONS vs control (189 vs 185). Meta-analysis was performed of nutritional intake, weight, mid-arm muscle circumference (MAMC) and handgrip strength (HGS) (Comprehensive Meta-analysis v2). Quality of life, exercise capacity and respiratory outcomes were also examined. In contrast to previous Cochrane reviews, examining only data at the end of intervention, ${ }^{1}$ this review examined the changes induced by ONS. Significantly improved energy intake was reported in six out of seven studies of which four were meta-analysable (+262 SE $104 \mathrm{kcal} / \mathrm{d}, \mathrm{p}=0.012$, random effect model, four RCT). Meta-analysis found ONS significantly improved body weight (+1.85 kg SE $0.25 \mathrm{~kg}, \mathrm{p}<0.001$ (malnourished) and $+1.31 \mathrm{~kg}$ SE $0.34 \mathrm{~kg}, \mathrm{p}<0.001$ (nourished), 11 studies) and had a tendency to improve MAMC $\left(+0.21 \mathrm{~kg}\right.$ SE $0.19 \mathrm{~kg}, \mathrm{p}=0.277$, fixed effect model; $\mathrm{I}^{2}=0 ; 2$ studies $)$. Improved HGS was found in three of four studies, two significant in their own right with meta-analysis favouring ONS $(+2.14 \mathrm{~kg} \mathrm{SE}$ $1.1 \mathrm{~kg}, \mathrm{p}=0.054$, random effect model ( $+8.3 \%$ improvement)). No improvements were reported in $\mathrm{FEV}_{1}$ (eight studies) however, respiratory muscle strength appeared more responsive to ONS with PI max improved in three out of five studies (NS), PE max significantly improved in two out of four studies and sternomastoid strength significantly improved in one study. Exercise tolerance (six out of seven studies), dyspnoea and general well-being (three out of five studies) and quality of life (two out of two studies) were significantly improved with ONS although meta-analysis of these outcomes was not possible. ONS result in significant improvements in nutritional intake and body weight and a tendency for improvements in several functional outcomes. This would support an increased level of evidence for ONS in the NICE COPD guidelines. 